\title{
Ethical Concerns and Your Career
}

By Julia VanDeren

Have an employer's business practices ever created ethical concerns for you? Have they affected your career?

It turns out the commitment to uphold the highest ethical standards within the investment management industry does not come without risks.

In a recent CFA Institute Financial NewsBrief poll, we asked readers if doubts about whether their employer's business practices were ethical have influenced their career trajectories. The results were both surprising and alarming.

Of the 485 total respondents, only $35 \%$ said their careers had never been affected by an employer's ethics. An additional $6 \%$ reported they were uncertain whether they had or not. That means well over half of participants believe ethics have influenced their professional trajectories. Despite the increased public and governmental emphasis on reforms and regulatory control, members still wrestle with ethical dynamics and the toll-positive or negative-they may have on their careers.

Moreover, $17 \%$ of poll respondents said their efforts to address ethical concerns directly affected their professional reputations. Unfortunately, only $5 \%$ believe their reputations benefited as a result, while $12 \%$ said they suffered.

This echoes the findings of a recent Harvard Business Review article, "Why Are Some Whistleblowers Vilified and Others Celebrated?" According to one of the authors, David M. Mayer, those in more senior roles are expected to resolve moral dilemmas and so are more likely to be celebrated for doing so. Individual contributors and lowerto mid-level managers, however, are more likely to be perceived as stepping out of line when they speak up, so their efforts often backfire.

One in five poll respondents reported avoiding a company or turning down a job offer due to ethical concerns. An additional 21\% said they left jobs because of such issues. This could be interpreted as a positive development. After all, you should aspire to have a career where your ethical values align with those of your employer. But, in a competitive job market, the need to restrict your search, turn down work, or even leave your position to uphold your moral standards can cause a great deal of stress and anxiety and is a unique career-management challenge.

I asked a few CFA charterholders and career coaches for advice on how people might position themselves after leaving a position because of ethical concerns. Most of their responses centered on how to handle subsequent job interviews.

Dixie Klaibert, CFA, and Sabrina Liak, CFA, the founders of FINVOGUE, a website devoted to financial careers, recommend framing the explanation along the lines of "We had differing perspectives on how to grow the business." Most interviewers will interpret this to mean cultural or ethical differences and will stop there. If they press for more information, Klaibert and Liak suggest responding with "They wanted to take on more risk than I was comfortable with." It's somewhat vague, but it is truthful.

"The important thing in any interview is to keep the discussion upbeat and positive," they continue. "Don't $\mathrm{dwell}$ on the past. If you complain about your previous employer, the interviewer might infer that you are not a team player." So concentrate on the skills

\section{Have ethical concerns about an employer's business practices ever affected your career?*}

Not at all.

I've had to leave a company because of my concerns about unethical business practices.

I've avoided companies in my job searches or turned down offers of employment because of ethics.

My professional reputation has suffered from identifying and attempting to correct unethical business practices.

I'm not sure.

My professional reputation has benefited from helping a company identify and correct unethical business practices.
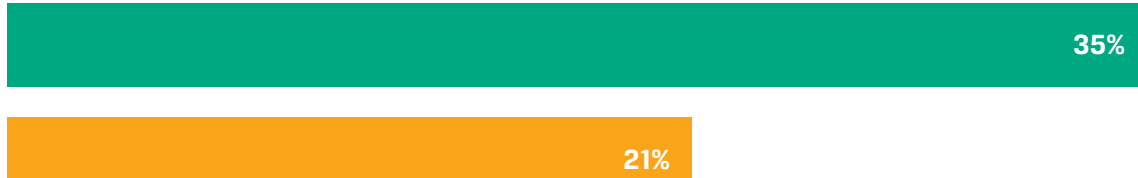

$20 \%$
$12 \%$ 
you bring to the table and express your enthusiasm for the position.

Jim Keene, CFA, founder of Atherton Consulting Group, has similar advice. "Do not reference unethical behavior at prior places of employment. There can be ambiguity around the line of ethi$\mathrm{cal} /$ unethical behavior, and it can lead to misunderstanding or interpretations by a new prospective employer. Frame any discussion around the decision to leave as a difference in core values between yourself and the firm that became apparent shortly before leaving. Direct the narrative in new prospective situations as a desire to match values and aspirations in an energizing and meaningful [way] at a new firm."

Career coach Robert Hellmann of Hellmann Career Consulting largely concurs with Klaibert, Liak, and Keene. Whatever your reason for moving on, you generally don't want to draw attention to it, he says. If a potential employer doesn't ask, don't feel obligated to bring up the circumstances. As he puts it, "Each situation requires a tailored response, but in general the strategy is to talk less, not more. And bring it back to how you can help them."

Ethical behavior exerts a powerful influence in the financial industry, whether it's on client relationships, investment objectives, or career management. It may be challenging, but the focus must remain on the value ethical behavior adds rather than its potentially negative influence.

If you are dealing with ethical issues in your career, whistleblowing, or the like, the CFA Institute Code of Ethics and Standards of Professional Conduct is an excellent reference. You might also consider seeking legal counsel.

Julia VanDeren is a career services representative at CFA Institute. This article was originally posted on Enterprising Investor (blogs.cfainstitute.org/investor).

\section{Grappling with Tough Questions}

\section{ARE YOU PREPARED TO PAY THE HIGH COST OF INTEGRITY?}

By Jennifer Simpson

Have you ever put extra energy into preparing for a big race, a big performance, or some other once-in-a-lifetime goal, only to be delayed by having to help others along? At work, have you ever been waylaid by requirements to stop and evaluate the implications for your client, your company, or the broader financial system? Where do you draw the line to determine when a responsibility is yours to bear versus someone else's problem?

In the 1983 article "The Parable of the Sadhu," Bowen McCoy, at the time a managing director at Morgan Stanley participating in a company-sponsored, experimental six-month sabbatical program, tells the story of his epic trip to Mt. Everest, during which he came face to face with his own humanity. Three groups of people from various countries were attempting the climb; though conditions were decent, they discovered a severely hypothermic sadhu (Hindu holy man) along their route. One group of climbers transported him down the mountain a bit, and another group bundled the sadhu using their outer layers and then went on their way. A third set fed him and pointed him in the right direction to the nearest town. But nobody was quite sure whether he survived, because they were more interested in their own survival and in their attempt to meet their goal of summiting.

McCoy and a friend on the trip debate the breakdown between the individual ethic and the corporate ethic. That day on Everest, says McCoy's friend, "no one person was willing to assume ultimate responsibility for the sadhu. Each was willing to do his bit just so long as it was not too inconvenient. When it got to be a bother, everyone just passed the buck to someone else and took off."

In finance and investing, this dilemma may also arise, whether in making investment decisions, structuring new products, or advising clients. The outcomes may affect individuals or may be as far-reaching as influencing the stability of the global financial system. Clients, employers, employees, and regulators may have competing needs and interests, but in the end, high-integrity leaders find a balance.

As a CFA charterholder, what would you have done if you were a part of the "Parable of the Sadhu" story? Envision yourself and the role you play in your clients' financial lives through this lens. Although your dilemmas may not involve choosing between life and death on the frozen face of Mt. Everest, there are important parallels in the challenges you face as a financial professional. The following principles from the CFA Institute Code of Ethics and Standards of Professional Conduct set forth important guideposts in this respect, serving as relevant touchpoints for when you come across sadhus in your practice and in your life:

- Place the integrity of the profession and the interests of clients above your own interests.

- Act with integrity, competence, and respect.

- Maintain and develop your professional competence.

Do you focus on the long term? Are you willing to compromise achieving your stretch goals to ensure the survival of the sadhus you encounter? How do you prepare your organization to deal with these issues when they arise and ensure that duty to client jibes with duty to employer?

We discuss these questions and more around our seminar tables in the Finance Leaders Fellowship. To learn more, visit www.aspeninstitute.org/flf.

Jennifer Simpson is the managing director of the Finance Leaders Fellowship at the Aspen Institute. 